Research Article

\title{
Comprehensive Pricing Scheme of the EV Charging Station considering Consumer Differences Based on Integrated AHP/DEA Methodology
}

\author{
Xingquan Ji, ${ }^{1}$ Ziyang Yin, ${ }^{1}$ Yumin Zhang ${ }^{D},{ }^{1}$ Xuan Zhang, ${ }^{1}$ Haishu Gao, ${ }^{1}$ and Xinyi Zhang ${ }^{2}$ \\ ${ }^{1}$ College of Electrical Engineering and Automation, Shandong University of Science and Technology, Qingdao 266590, China \\ ${ }^{2}$ Qingdao Electric Power Supply Company of State Grid Shandong Electric Power Company, Qingdao, China
}

Correspondence should be addressed to Yumin Zhang; ymzhang2019@sdust.edu.cn

Received 18 August 2020; Revised 25 September 2020; Accepted 27 September 2020; Published 10 October 2020

Academic Editor: Ruben Specogna

Copyright (c) 2020 Xingquan Ji et al. This is an open access article distributed under the Creative Commons Attribution License, which permits unrestricted use, distribution, and reproduction in any medium, provided the original work is properly cited.

Scientific pricing of the electric vehicle charging station is closely related to consumer behavior inevitably. Existing studies have not considered the impacts of consumer differences on the charging price, which will fail to meet the interests of various types of consumers. This paper proposes a novel pricing method based on consumer classification and comprehensive evaluation strategies. First, the basis for consumer classification is established according to a single factor sensitivity analysis of the consumer benefit model; then, the nonlinear expression of the basis is piecewise linearized. Additionally, with the principle of least fitting error to determine consumers' classification, the initial charging price schemes for various types of consumers are formulated. Second, this paper defines evaluation indices and establishes the hierarchy model for comprehensive evaluation schemes. Finally, the integrated analytic hierarchy process and data envelopment analysis are adopted for comprehensive evaluation of schemes. Simulations results illustrate that the proposed method can formulate the comprehensive optimal charging price considering consumer differences, and the method can reflect the impacts of both subjective and objective factors conveniently and accurately.

\section{Introduction}

Electric vehicles (EVs) can reduce greenhouse gas emissions and alleviate vehicle excessive dependence on petroleum resources [1]. Research efforts are focusing on energy security and low-carbon economy, and under this situation, EVs have become one of the primary choice alternatives for conventional fuel cars [2]. With a series of government public policies support, Shandong province will build 350000 charging posts in five years [3]. Tianjin has built 143 charging/switching stations, which has realized a complete coverage of whole city [4]. All these mean that the consumers using EVs are increasing rapidly. EVs are becoming a large-scale development trend as consumers seek ways to reduce emissions to protect the environment [5-7].

There are several factors influencing consumer preferences, and several studies have been conducted to understand how public policy affects consumer choices, manufacturer decisions, and EV market growth [2] that establishes the market model of Chinese EVs considering eight attributes. In [8], the authors analyze the consumers' attitude and demand for the EVs and indicates that the purchase price and usage cost are the most important factors for purchase preferences of consumers. In [9], the authors address that consumer preferences are affected by relationships between the product and service price of EV. In [10], the authors compare and calculate total lifecycle costs (TLCC) of EVs with TLCC of the gasoline vehicle based on the various driving range and the gasoline price, and the results indicate that TLCC of EV is more than TLCC of gasoline vehicles. In [11], the authors address the operation cost of the EV charging infrastructure, and the simulation results show that it is difficult for the EV charging infrastructure to gain profits. In [12], the authors give a pricing range of the EV charging station, which can not only ensure the profit of station operators but also improve the profit of 
consumers compared to using the internal-combustionengine vehicle. In [13], the authors present a methodology to assess the coat-benefit and develop the service pricing strategy of electric taxies in Shanghai, China. Therefore, the service pricing of charging is the crucial problem to encourage consumer to using EVs. The charging station is one of the indispensable components in the operation of the EV industry [14]. The charging prices of the charging station are the fees how much the consumers should pay the charging station operators for a certain amount of charging electricity (the sum of electricity and charging service charges). It is not only the important reference factor for vehicle buyers to choose EVs rather than ICV but also the main way for operators to recover the cost of investment in charging infrastructure and even is the principal means for power companies to motivate EVs consumers to change their charging behaviors to optimize the distribution of the power load [15]. Therefore, the reasonable pricing of EVs is the key problem to promote the development of the EV industry.

In order to establish a reasonable charging servicing price, various forms of charging price strategies are formulated and implemented overseas and in China [16-19]. On the cost of self-charging at home, the standard electricity tariffs of EVs charging prescribed by the United States California Pacific Gas and Electric Company (PGEC) are based on the residential pricing, and the time-of-use (TOU) price is set from 5 cents/kWh to 28 cents/kWh $[20,21]$. Japan implements the preferential policies for free charging in the stage of demonstration. Some cities in China, such as Hangzhou, have also launched their own local policies, and the pricing of EV charging is based on the method of costbenefit income. However, this pricing has prompted EVs to operate too costly, which is not conducive to the promotion of the EVs industry [22]. The National Development and Reform Commission of China (NDRC) issues that China implements the supportive policy on the price of $\mathrm{EV}$ charging, and the service fees of electric vehicle charging stations are performed by the local according to the principle of "preferential and discount" with the government guidance pricing management. Meanwhile, the NDRC gives a preferential price to the centralized charging stations for the purpose of business and implements large industrial electricity prices. The charging service fees are gradually formed through market competition with the development of market [23]. Since June 2015, Beijing has charged the service fees according to the capacity of charge up for battery. The upper limit standard of the charge per kilowatt-hour is equal to $15 \%$ of the highest retail price of No. 92 gasoline per liter on the same day of the city. In addition, until January 2020, the electric vehicle charging service fees will perform the price of market regulation in accordance with the provisions of the state [24]. Xinjiang has outlined a standard EVs charging service fee; the upper limit of tentative price of the electric vehicle charging fee is $1.2 \mathrm{RMB}$ yuan/kWh, and the upper limit of the electric bus charging fee is temporarily set $1 \mathrm{RMB}$ yuan/kWh [25].

The market mechanism can promote the development of the EVs industry. The positive influence of the commercial TOU price on the operation benefit of EVs charging is discussed in [26]. San Diego Gas and Electric Company establishes an analysis model considering the impacts of TOU price on the charging behaviors. The model assesses the relationship between the position of charging infrastructure (residential and nonresidential areas) and charging price and determines three kinds of charging price schemes, which the private EV consumers can choose [27]. With the rapid growth of charging stations for EVs, EVs charging/ switching business modes become more important. However, from the views of both EVs operators and consumers, a more reasonable charging price considering various types of consumers has not been established.

In the initial development of EVs, the price of $\mathrm{EV}$ charging does not have the conditions to determine the price based on market competition. The comprehensive cost pricing, which can balance the interests of all parties and ensure the operating income, is more advantageous to promote the development of EVs [22]. In principle, the pricing of the EVs charging station should consider the tripartite interests of the government, operators, and consumers [28]. In [12], based on the Game theory, the authors construct the benefit models of EV operators and consumers in terms of the standard charging stations and the standard EV. They also calculate a reasonable pricing range for charging. In [29], the authors further consider the influence of the time value of money in project, TOU, and the level of government subsidies.

Visibly, for formulation of charging price, it is vital to fully consider the influence of various factors and improve the comprehensive cost pricing model [30]. However, in current studies, the EV consumers are often considered as only one type (standard or typical), which is not consistent with the fact that consumers have very visible individual difference, and thus, the pricing of EV charging will not achieve the expected effect.

Accordingly, the individual difference of consumers should be taken into consideration in the pricing of EV charging, and the comprehensive evaluation of EV charging price should be solved effectively. The Analytic Hierarchy Process (AHP) [31] and Data Envelopment Analysis (DEA) [32] are the common comprehensive evaluation methods, which are widely used in all kinds of decision-making problems. In $[33,34]$, the authors explore the use of hierarchical structure for classifying evaluation indices and employ the integrated AHP/DEA method in the different stages of evaluation, which verifies the more practicality and effectiveness in dealing with complex problems.

Because the private EV is becoming increasingly prevalent as a means of transportation accounting for $85 \%$ of the civilian cars [35]. Considering that the individual consumer is more sensitive to the price of EV charging, this paper takes the private EV as an analysis object and proposes a novel pricing method of EV charging considering the consumer differences. First, set up the pricing method considering the interests both of EV charging stations' operators and consumers comprehensively. Then, based on the analysis of the factors affecting consumer interest changes, this paper adopts the single factor sensitivity analysis to determine the principle of consumer classification and puts forward the 
method of consumer classification. Finally, this paper establishes the hierarchy model of evaluation, defines the evaluation index, and gives the calculation method of index. The optimal price for all types of consumers can be obtained through the comprehensive decision-making of the initial charging prices schemes based on the AHP/DEA method. The effectiveness of the proposed method can be illustrated using an actual EV charging station. Simulation results verify that the optimal charging prices applying to different types of consumers can be determined, and it can conveniently reflect the demand response to price changes; thus, the expected demand can be obtained by adjusting the price.

\section{The Methods on the Pricing of EV Charging}

2.1. A Win-Win Pricing Strategy for Operator and Consumer. If the pricing of EVs charging is conducive to the EVs industry promotion, it should follow the principle that both the consumers' comparative benefit (the use cost of EVs less than the use cost of the traditional internal-combustionengine vehicle (ICV)) and the operators' benefit (operator can profit) are positive. So, the reasonable pricing of $\mathrm{EV}$ charging should balance the interests of both consumers and operators.

$$
Y_{i}(t)=\mathrm{CI}_{i}-\mathrm{CO}_{i} \geq 0, \quad i=1,2,
$$

where $Y_{1}$ is the benefit function of EVs operators. $Y_{2}$ is the comparative benefit of consumers. CI and $\mathrm{CO}$ are, respectively, the amounts of cash inflows and cash outflows. Figure 1 illustrates the structure chart of cash inflows and cash outflows based on the EVs charging mode.

The benefit model reflecting the interests of operators and consumers can be constructed by analyzing the main factors influencing the cost-benefit of operators and consumers. Assume that the EV battery life is 8 years and the project cycle is 16 years; then, the benefit function of operators and the comparative benefit function of consumers are shown in (2) and (3), respectively [26].

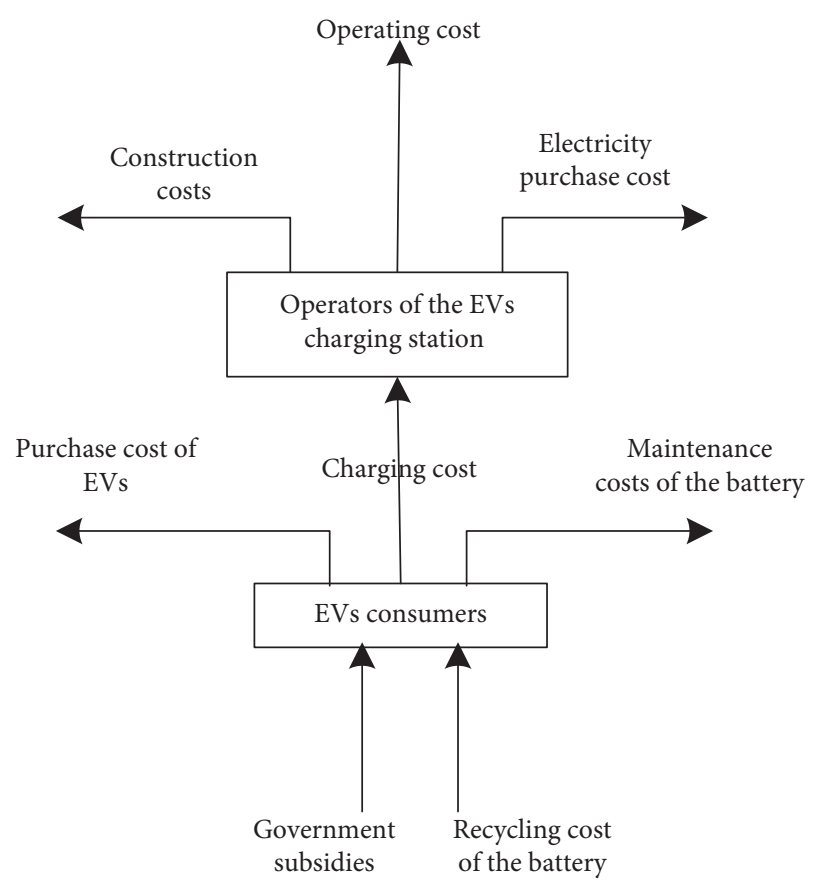

FIgURE 1: Structure chart of cash inflows and cash outflows based on the EVs charging mode.

$$
Y_{1}(t)= \begin{cases}Q_{c} \cdot \pi_{c}-\left(\frac{Q_{c} \cdot \pi_{p}}{\eta}+S_{b}+S_{r}\right), & t=0, \\ Q_{c} \cdot \pi_{c}-\left(\frac{Q_{c} \cdot \pi_{p}}{\eta}+S_{r}\right), & t \geq 1,\end{cases}
$$

where $Q_{c}$ is the annual charging capacity of the charging stations. $\pi_{c}$ and $\pi_{p}$ are the charging prices and the feed-in tariffs (FITs), respectively. $\eta$ is the loss of EV charging. $S_{b}$ and $S_{r}$ are, respectively, the station construction cost and the operating cost. Table 1 illustrates the parameters settings value on the benefit function of EVs operators.

$$
Y_{2}(t)=\left\{\begin{array}{l}
\left(\Delta C_{v}+D_{\mathrm{mil}} \cdot F_{\mathrm{pm}} \cdot \pi_{f}\right)-\left(B_{\mathrm{pe}} \cdot E_{\mathrm{av}}+D_{\mathrm{mil}} \cdot E_{\mathrm{pm}} \cdot \pi_{c}+D_{\mathrm{mil}} \cdot E_{\mathrm{pm}} \cdot B_{\mathrm{pm}}\right), \quad t=0, \\
\left(D_{\mathrm{mil}} \cdot F_{\mathrm{pm}} \cdot \pi_{f}\right)-\left(D_{\mathrm{mil}} \cdot E_{\mathrm{pm}} \cdot \pi_{c}+D_{\mathrm{mil}} \cdot E_{\mathrm{pm}} \cdot B_{\mathrm{pm}}\right), \quad t \geq 1, \text { and } t \neq 8, t \neq 16, \\
\left(D_{\mathrm{mil}} \cdot F_{\mathrm{pm}} \cdot \pi_{f}+B_{\mathrm{pr}} \cdot E_{\mathrm{av}}\right)-\left(D_{\mathrm{mil}} \cdot E_{\mathrm{pm}} \cdot \pi_{c}+D_{\mathrm{mil}} \cdot E_{\mathrm{pm}} \cdot B_{\mathrm{pm}}\right), \quad t=8, \text { or } t=16,
\end{array}\right.
$$

where $\Delta C_{v}=C_{\mathrm{icv}}-\left(C_{\mathrm{ev}}-\mathrm{CI}_{g}\right)$ is the difference between the purchase cost of the internal-combustion-engine vehicle and the nude EV after subsidy. $D_{\text {mil }}$ and $t$ are the annual distance driven of EV and the service time, respectively. $\pi_{f}$ and $F_{\mathrm{pm}}$ are the fuel price and the fuel consumption per kilometer, respectively. $E_{\mathrm{av}}$ is the average electricity capacity of the battery. $E_{\mathrm{pm}}$ is the electricity consumption per kilometer. $B_{\mathrm{pe}}, B_{\mathrm{pr}}$, and $B_{\mathrm{pm}}$ are, respectively, the purchase cost per unit energy of the battery, recycling price, and maintenance costs. Visibly, the main factors influencing operators and consumers are the service charges converted by the charging electricity tariffs, siting costs, and operating costs. Table 2 illustrates the parameters settings value on the comparative benefit function of the consumer.

According to the cost-benefit principle, the economic indicators of profitability with the net present value (NPV) as the inspection cycle [26], the minimum profitable charging price for EVs operators is

$$
\left\{\pi_{c 1}\left|\mathrm{NPV}_{1}=\sum_{t=0}^{T} Y_{1}(t)\left(1+i_{0}\right)^{-t}\right| \pi_{c}=\pi_{c 1} \geq 0\right\} .
$$


TABLe 1: Parameters settings on the benefit function of EVs operators.

\begin{tabular}{lccc}
\hline Parameters & Title & Value & Unit \\
\hline$Q_{c}$ & Annual charging capacity of charging stations & 200 & $10^{4} \mathrm{kWh}$ \\
$\pi_{c}$ & Charging prices & 1.78 & $\mathrm{RBM}$ yuan/kWh \\
$\pi_{p}$ & Price of buying electricity from grid feed-in tariffs (FITs) & 0.74 & $\mathrm{RBM}$ yuan/kWh \\
$\eta$ & Loss of EVs charging & 0.92 & $\%$ \\
$S_{b}$ & Cost associated with providing charging infrastructure of EVs charging stations & 2415 & $\mathrm{RBM} 10^{4}$ yuan \\
$S_{r}$ & Operating costs & 71.8 & $\mathrm{RBM} 10^{4}$ yuan \\
\hline
\end{tabular}

TABLe 2: Parameters settings on the comparative benefit function of consumers.

\begin{tabular}{|c|c|c|c|}
\hline Parameters & Items & Value & Units \\
\hline$\Delta C_{v}=C_{\mathrm{icv}}-\left(C_{\mathrm{ev}}-\mathrm{CI}_{\mathrm{g}}\right)$ & The difference between the purchase cost of the ICV and the nude EV after subsidy & -3 & RMB10 4 yuan \\
\hline$C_{\mathrm{icv}}$ & Purchase cost of the ICV & 10 & $\mathrm{RMB} 10^{4}$ yuan \\
\hline$C_{\mathrm{ev}}$ & Purchase cost of the nude EVs & 15 & RMB10 $0^{4}$ yuan \\
\hline $\mathrm{CI}_{g}$ & Government subsidies & 2 & RMB10 $0^{4}$ yuan \\
\hline$D_{\text {mil }}^{g}$ & Annual distance driven of the $\mathrm{EV}$ & 25000 & $\mathrm{~km} /$ year \\
\hline$T$ & Annual service time of EVs & & $\mathrm{h}$ \\
\hline$\pi_{f}$ & Fuel price & 7.45 & $\mathrm{RMB}$ yuan/L \\
\hline$F_{\mathrm{pm}}$ & Fuel consumption per kilometer & 0.069 & $\mathrm{~L} / \mathrm{km}$ \\
\hline$E_{\text {av }}$ & Average electricity capacity of the battery & 16 & $\mathrm{kWh}$ \\
\hline$E_{\mathrm{pm}}$ & Electricity consumption per kilometer & 0.14 & $\mathrm{kWh} / \mathrm{km}$ \\
\hline$B_{\mathrm{pe}}$ & Purchase cost per unit energy of the battery & 3000 & RMB yuan/kWh \\
\hline$B_{\mathrm{pr}}$ & Recycling price per unit energy of the battery & 900 & RMB yuan/kWh \\
\hline$B_{\mathrm{pm}}$ & Maintenance costs per unit energy of the battery & 0.5 & RMB yuan/kWh \\
\hline
\end{tabular}

The maximum acceptable charging price for consumers is

$$
\left\{\pi_{c 2}\left|\mathrm{NPV}_{2}=\sum_{t=0}^{T} Y_{2}(t)\left(1+i_{0}\right)^{-t}\right| \pi_{c}=\pi_{c 2} \geq 0\right\},
$$

where $T$ is the benchmark payback period of investment, and $T=16 . i_{0}$ is the benchmark yield, and this paper takes $5 \% . \pi_{c 1}$ and $\pi_{c 2}$ are the acceptable reasonable charging prices for operators and consumers, respectively. Then, the acceptable reasonable charging price range for both operators and consumers is

$$
\left\{\pi_{c} \mid \pi_{c 1} \leq \pi_{c} \leq \pi_{c 2}\right\}
$$

2.2. Construction Cost of EVs Charging Stations. An EVs charging station generally contains the building part, charging part, distribution, monitoring, communication and security, fire control part, and other costs. The construction costs associated with providing charging infrastructure of EVs charging stations are shown in Table 3.

The annual operation costs of an EVs charging station generally contains labor costs, utility bills, communication fees, upkeep cost of battery, and minimum attractive rate of return. The operating costs of EVs charging stations are shown in Table 4.

\section{Consumer Classification}

3.1. The Basis of Consumer Classification. As shown in (2), a part of the factors affecting consumers' comparative benefits has obvious individual differences, and the determined price using the single parameter to represent all consumers will fail to the accuracy. Therefore, if the consumer differences are considered in formulation of the charging prices, the model corresponding to consumer classification will be established, and it can take the interests of different types of consumers into account.

The differences of the purchase cost of the EV affect the charging prices; however, it is not relevant to the behavior of the individual consumer using the EV. Therefore, this article does not consider the cost differences. In (2), with the indepth study of the parameters such as the fuel tax of the ICV, the prices of EV charging, and maintenance costs of the battery, it can be found that they are all associated with the annual distance driven. In order to further clarify the key factors influencing the comparative benefit of consumers, it is necessary to perform the single-parameter sensitivity analysis for the comparative benefit of consumers [36].

The sensitivity of evaluation index to the influence factor can be expressed with sensitivity coefficient.

$$
S_{\mathrm{AF}}=\frac{\Delta A / A}{\Delta F / F}
$$

where $S_{\mathrm{AF}}$ is the sensitivity coefficient. $\triangle A / A$ is the change rate of evaluation index. $\Delta F / F$ is the change rate of the influence factor. $\left|S_{\mathrm{AF}}\right|$ is bigger, namely, the sensitivity coefficient is high, and it illustrates that the role of influence factors cannot be ignored.

Based on the comparative benefit model of consumers [26], this paper takes the NPV of consumers in a certain period as the evaluation index and takes the standard types of consumers and the parameters of the EV charging station as the base value. Assume that the change range of each 
TABLE 3: Construction cost associated with providing charging infrastructure of EVs charging stations.

\begin{tabular}{|c|c|c|c|c|}
\hline Zone & Items & Number & Cost (RBM $10^{4}$ yuan) & Cost (RBM $10^{4}$ yuan) \\
\hline \multirow{4}{*}{ Building part } & Civil part & 1 set & 350.53 & \multirow{4}{*}{467.67} \\
\hline & HVAC part & 1 set & 37.36 & \\
\hline & Water supply and drainage part & 1 set & 42.82 & \\
\hline & Civil electrical part & 1 set & 36.96 & \\
\hline \multirow{3}{*}{ Charging part } & Off-board charger for EVs & 19 sets & 420.11 & \multirow{3}{*}{1102.61} \\
\hline & AC charging posts & 30 & 217.5 & \\
\hline & DC charging posts & 30 & 465 & \\
\hline \multirow{4}{*}{$\begin{array}{l}\text { Distribution, monitoring, } \\
\text { communication and security, } \\
\text { and fire control }\end{array}$} & $800 \mathrm{kVA}$ dry-type transformers & 2 & 262.44 & \multirow{4}{*}{408.97} \\
\hline & Supervision infrastructure & 1 & 73.08 & \\
\hline & Communication infrastructure & 1 & 35.88 & \\
\hline & Security and fireproofing & 1 & 37.57 & \\
\hline \multirow{3}{*}{ Other cost } & Compile annually spreads & 1 & 13.06 & \multirow{3}{*}{435.75} \\
\hline & Fixed other fee & 1 & 366.05 & \\
\hline & Loan interest in the construction period & 1 & 56.64 & \\
\hline Total cost & \multicolumn{4}{|c|}{2415} \\
\hline
\end{tabular}

TABLE 4: Operating costs of the EVs charging station.

\begin{tabular}{lcc}
\hline Items & Cost (RMB $10^{4}$ yuan) & Calculation basis and remarks \\
\hline Annual labor costs & 46.8 & Annual labor cost $=13$ (persons) $\times 3000$ yuan $/$ month $\times 12$ month \\
Annual utility bills & 5 & Experience value \\
Annual communication fees & 10 & $\begin{array}{l}\text { Experience value } \\
\text { Experience value }\end{array}$ \\
Annual upkeep cost of battery & 10 & $\begin{array}{c}\text { Calculate according to the slightly higher than the } \\
\text { three-year certificate of the deposit rate }\end{array}$ \\
Minimum attractive rate of return & $5 \%$ & \\
\hline Total & 71.8 & \\
\hline
\end{tabular}

factor is $\pm 10 \%$; then, the single-parameter sensitivity analysis for the comparative benefit of consumers is shown in Table 5.

As shown in Table 1, the fuel consumption per kilometer and oil price have the highest sensitivity among all parameters, both of them are the parameters related to the traditional ICV, and they are not relevant to consumer behavior. The second is the annual distance driven, and it is the primary factor associated with consumer behavior. However, all the other factors having higher sensitivity are not relevant to the consumer behavior. Therefore, the annual distance driven can be regarded as the main basis of consumer classification.

3.2. The Method of Consumer Classification. Assume that the travel behavior of the private $\mathrm{EV}$ is consistent with the rules of the traditional fuel vehicle [37]; according to the findings of the U.S. Department of Transportation about the National Household Travel Survey (NHTS) [38], the distribution function curve of the proportion of consumers and the daily distance driven are shown in Figure 2.

Based on above analysis, the method of classifying consumers according to the annual distance driven can be established as follows:

(1) Select the appropriate samples, that is, the maximum distance and the minimum distance should be eliminated. The daily distance driven of consumers is less than $10 \mathrm{~km}$, the distance is very short, and the impact of charging prices on it is very small. Therefore, this part of consumers can be ignored. As well as, the part of consumers whose daily distance driven is more than $120 \mathrm{~km}$. So, this paper chooses the consumers whose daily distance driven range is $10 \mathrm{~km}-120 \mathrm{~km}$ (accounting for $73 \%$ of the total samples) as the sample to study.

(2) The piecewise linearization of the curve and the segment results can be determined based on minimum fitting error. Each piecewise corresponds to a type of consumers, and the fitting error $e$ can be expressed using the average value of the standard deviation.

$$
e=\frac{1}{N} \sum_{i=1}^{N} \sqrt{\frac{1}{n-1} \sum_{j=1}^{n}\left(\frac{x_{i}-\widehat{x}}{x_{i}}\right)^{2}}
$$

where $N$ is the number of segments of the piecewise linearized curve. $x_{i}$ is the true value of curve. $\widehat{x}$ is the linear approximation value of $x_{i} . n$ is the number of fitting points.

Table 6 illustrates the segment results on the distance driven range of consumers, the distribution curve of the proportion of consumers, and the corresponding fitting error. The best is that consumers are divided into four types. Meanwhile, the fitting error of 
TABLE 5: The single-parameter sensitivity analysis for the comparative benefit of consumers.

\begin{tabular}{lccccc}
\hline Parameter & $+10 \%$ & 0 & $-10 \%$ & $S_{\mathrm{AF}}$ & Sensitivity rank \\
\hline$\Delta C_{v}$ & 1.74 & 1.44 & 1.14 & 2.08 & 8 \\
$D_{\mathrm{mil}}$ & 2.62 & 1.44 & 0.61 & 8.19 & 3 \\
$F_{\mathrm{pm}}$ & 3.10 & 1.44 & -0.10 & 11.53 & 1 \\
$\pi_{f}$ & 2.98 & 1.44 & -0.10 & 10.69 & 2 \\
$B_{\mathrm{pe}}$ & 0.63 & 1.44 & 2.24 & 5.63 & 6 \\
$E_{\mathrm{av}}$ & 0.79 & 1.44 & 2.08 & 4.51 & 7 \\
$E_{\mathrm{pm}}$ & 0.37 & 1.44 & 2.62 & 7.43 & 4 \\
$\pi_{c}$ & 0.61 & 1.44 & 2.39 & 5.76 & 5 \\
$B_{\mathrm{pm}}$ & 1.20 & 1.44 & 1.68 & 1.67 & 9 \\
\hline
\end{tabular}

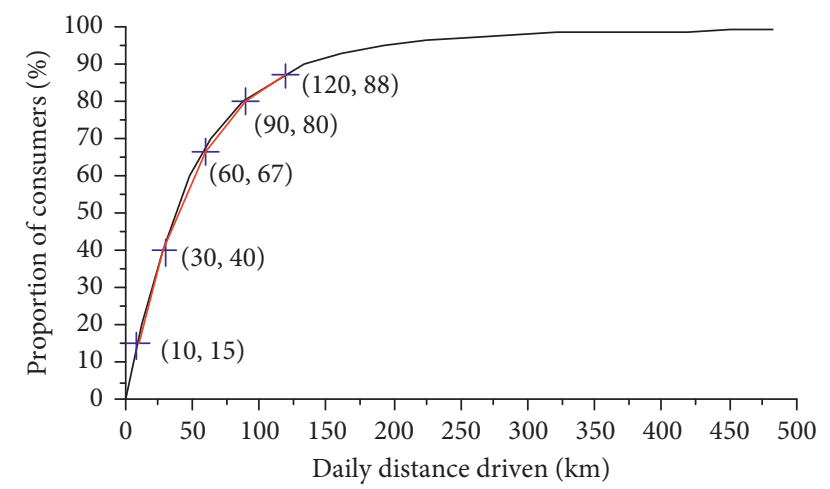

Figure 2: The daily distance driven of consumers and the corresponding proportion.

piecewise linearization cure is the minimum, and the segment results are shown in Figure 2.

(3) Determine the typical values of consumers. Because the daily distance driven of each consumer and the corresponding distribution curve of the proportion of consumers are approximate linear relationship. Therefore, the average value of the daily distance driven of each consumer can be regarded as the typical values of distance driven of this consumer. Based on the typical values of consumers, the acceptable charging price of this type of consumer can be determined to form the initial charging price scheme.

\section{Comprehensive Decision-Making of Charging Prices}

4.1. The General Principle of Charging Price Evaluation. The comprehensive evaluation of the EV charging price scheme and the decision-making goal are to select a comprehensive optimal electricity price scheme, which should consider the economic interests of both the operators and consumers, and have good applicability and relatively higher level of satisfaction. For this purpose, this paper defines the evaluation criteria such as the economy, applicability, satisfaction, and the specific indices, which can be expressed as follows.
TABLE 6: The segment results of consumers and the corresponding fitting error.

\begin{tabular}{lccc}
\hline \multirow{2}{*}{ Piecewise block $(\mathrm{km})$} & \multicolumn{3}{c}{ Number of segments } \\
& 3 & 4 & 5 \\
\hline Shorter & & & $(10-32)$ \\
Shorter & $(10-40)$ & $(10-30)$ & $(32-54)$ \\
Middle & $(40-80)$ & $(30-60)$ & $(54-76)$ \\
Long & $(80-120)$ & $(60-90)$ & $(76-98)$ \\
Longer & & $(90-120)$ & $(98-120)$ \\
$e$ & 0.033 & 0.006 & 0.008 \\
\hline
\end{tabular}

(1) Economy $\left(P_{1}\right)$ : it illustrates whether the evaluation scheme is conducive to the economic index of the participants.

Specific indices: taking the internal rate of return $\left(I_{1}\right)$ and dynamic payback period $\left(I_{2}\right)$ of consumers as indices to describe the economy of consumers, the higher $I_{1}$, the smaller $I_{2}$, and it illustrates that the better the economy of consumers to use the EV. Taking the NPV $\left(I_{3}\right)$ and the dynamic payback period $\left(I_{4}\right)$ of the operators as indices to describe their economy, the higher $I_{3}$, the smaller $I_{4}$, and it illustrates that the better the profitability of the EV charging station.

(2) Applicability $\left(P_{2}\right)$ : the index of the evaluation scheme considering the function of each type of consumer.

Specific indices: the proportion of consumer corresponding to charging price $\left(I_{5}\right)$ and the standard deviation of relative error of piecewise linearized distance driven of consumers $\left(I_{6}\right)$ express the application, the higher $I_{5}$, the smaller $I_{6}$, and it illustrates that the wider the applicable range of the charging prices, the better the applicable ability.

(3) Satisfaction $\left(P_{3}\right)$ : the index of acceptable degree of participants to evaluation scheme.

Specific indices: the spread between charging prices and expected price of operators $\left(I_{7}\right)$, and the spread between determined charging price and strike charging price $\left(I_{8}\right)$ express the satisfaction of participants. The smaller $I_{7}$, the higher $I_{8}$, and it means higher participants satisfaction. Meanwhile, the higher the consumers' acceptable price, the more consumers' surplus, the easier consumer satisfaction with the charging prices, and the more beneficial to the promotion of the EV industry.

\subsection{Establish Evaluation Criteria and Determine the Weight of} all Indexes Using AHP. As analyzed in Section 4.1, the comprehensive evaluation of charging price is a decisionmaking problem with multilevel and multifactor, and the hierarchical structure of the model is shown in Figure 3.

When using AHP to evaluate the charging price, if you want to rank all the schemes in order, first, you should determine the relative importance among all factors of criteria hierarchy, that is, weight. The method to determine the weight of criteria hierarchy is as follows: 


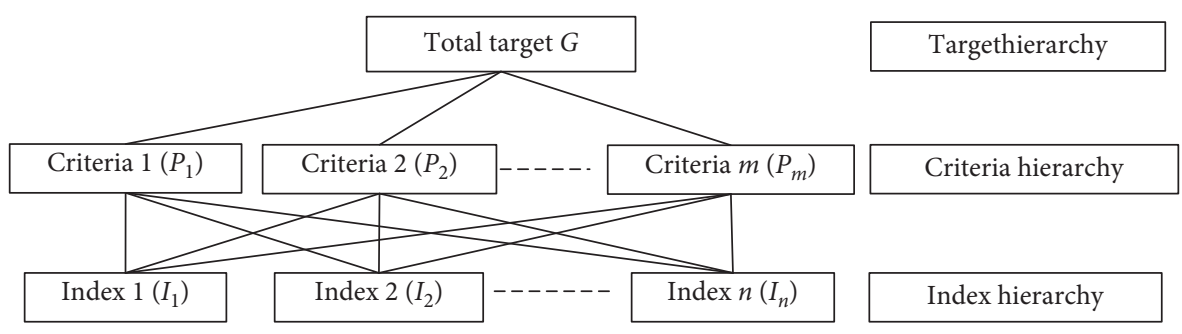

FIgURE 3: Hierarchy model for comprehensive evaluation.

(1) Determine the weight of criteria hierarchy. Because the number of the criteria hierarchy is less, the difference among the criteria is very visible. This paper adopts the 1 9 scale method to construct the judgment matrix $P$, which realizes the quantitative comparison of each element on the same hierarchy. If there are $m$ criteria related to the overall goal, the judgment matrix is

$$
\mathbf{P}=\left[\begin{array}{cccccc}
P_{11} & P_{12} & \cdots & P_{1 j} & \cdots & P_{1 m} \\
P_{21} & P_{12} & \cdots & P_{2 j} & \cdots & P_{2 m} \\
\vdots & \vdots & & \vdots & & \vdots \\
P_{i 1} & P_{i 2} & \cdots & P_{i j} & \cdots & P_{i m} \\
\vdots & \vdots & & \vdots & & \vdots \\
P_{m 1} & P_{m 2} & \cdots & P_{m j} & \cdots & P_{m m}
\end{array}\right],
$$

where the values of $P_{i j}(i, j=1,2, \ldots, n)$ are $1,3,5,7$, and 9 . They, respectively, denote the different degrees from the equal importance to extreme importance comparing criterion $i$ with criterion $j$. When we need to refine the value of importance, $P_{i j}$ can also be 2,4 , 6 , and 8 .

(2) Determine the weight between criteria hierarchy and the target hierarchy. The square root method [19] is usually adopted to determine the weight value.

First, calculate the product $M_{i}$ of all elements in every row of the judgment matrix $P$.

$$
M_{i}=\prod_{j=1}^{n} P_{i j}, \quad i=1,2, \ldots, m .
$$

Then, calculate the $m^{\text {th }}$ root of $M_{i}$.

$$
\bar{w}_{i}=\sqrt[m]{M_{i}}, \quad i=1,2, \ldots, m
$$

Finally, $\bar{W}_{i}=\left[\bar{w}_{1}, \bar{w}_{2}, \ldots, \bar{w}_{m}\right]^{T}$ is normalized.

$$
w_{i}=\frac{\bar{w}_{i}}{\sum_{j=1}^{m} \bar{w}_{j}}, \quad i=1,2, \ldots, m .
$$

Then, the coefficient vector constituted (of) by $w=\left(w^{P_{1}}, w^{P_{2}}, \ldots, w^{P_{m}}\right)$ is the relative weight of each criterion. Similarly, the weight of the index hierarchy relative to a certain criterion can be obtained.

The basis constructing the judgment matrix is qualitative subjective judgment of the decision-makers; however, the number of indices in index hierarchy is more, and the importance of each index is difficult to distinguish subjectively. Meanwhile, each index exists a correlation with multiple criteria at the same time. Adopting the judgment matrix will affect the objectivity of the final result. Therefore, this article only adopts the DEA model, which has better objectivity to analyze the index hierarchy.

4.3. The Charging Prices Schemes are Ranked under the Single Criterion Using DEA. According to the foregoing discussion, the input and output index sets of the economy, applicability, and satisfaction of evaluation schemes are shown in Table 7. The calculation method of each economic index can be seen in [26], and the other indices can be obtained by definition.

The DEA method regards the need decision-making scheme as the decision-making unit (DMU). Assume that there are $n$ DMU; each DMU has $m$ input $x$ and $s$ output $y$; they are, respectively, the consume cost of resource caused by the DMU and the benefit produced by DMU. Then, the efficiency evaluation of a certain evaluation criterion for the $k(1 \leq k \leq n)$ DMU is performed, and the optimization problem on the variables with the input weight coefficient of $v=\left(v_{1}, v_{2}, \ldots, v_{m}\right)$ and the output weight coefficient $u=$ $\left(u_{1}, u_{2}, \ldots, u_{m}\right)$ can be formed, as shown in the following equationfd12.

$$
\left\{\begin{array}{l}
\max \frac{u^{T} y_{k}}{v^{T} x_{k}}=V_{k}^{P} \\
\text { s.t. } \quad \frac{u^{T} y_{j}}{v^{T} x_{j}} \leq 1, \\
j=1,2, \ldots, n, v \geq 0, u \geq 0,
\end{array}\right.
$$

where $x_{j}=\left(x_{1 j}, x_{2 j}, \ldots, x_{m j}\right)^{T}$ and $y_{j}=\left(y_{1 j}, y_{2 j}, \ldots, y_{s j}\right)^{T}$ $j=1,2, \ldots, n . V_{k}^{P}$ is the optimal efficiency index for the $k^{\text {th }}$ DMU under the evaluation criteria.

Therefore, the evaluation is transferred into ranking for relative effectiveness of multiple DMU, which enhances the objectivity of the evaluation decision-making. The optimal efficiency indices $V_{k}^{P_{1}}, V_{k}^{P_{2}}$, and $V_{k}^{P_{3}}$ can be obtained by calculating the input index and the output index in Table 7.

\subsection{Comprehensive Evaluation of Initial Charging Price} Scheme. When the weights of evaluation criteria and the ranks of the schemes under the single evaluation criterion are determined, the comprehensive ranking of each DMU 
TABLE 7: The index sets of the economy, applicability, and satisfaction of evaluation scheme.

\begin{tabular}{lcc}
\hline Evaluation criteria & Input index & Output index \\
\hline Economy, $P_{1}$ & $I_{2}, I_{4}$ & $I_{1}, I_{3}$ \\
Applicability, $P_{2}$ & $I_{6}$ & $I_{5}$ \\
Satisfaction, $P_{3}$ & $I_{7}$ & $I_{8}$ \\
\hline
\end{tabular}

for the total target of evaluating can be normalized, and the weighted sum can be got according to (13). Then, the comprehensive evaluation of initial scheme can be carried out according to the size of the comprehensive sequencing weight $Q_{i}$, the greater the $Q_{i}$, the better the corresponding scheme.

$$
Q_{i}=w^{P_{1}} \frac{V_{i}^{P_{1}}}{\sum_{i=1}^{4} V_{i}^{P_{1}}}+w^{P_{2}} \frac{V_{i}^{P_{2}}}{\sum_{i=1}^{4} V_{i}^{P_{2}}}+w^{P_{3}} \frac{V_{i}^{P_{3}}}{\sum_{i=1}^{4} V_{i}^{P_{3}}} .
$$

It should be pointed out that the input indices and output indices must be positive due to the limitations of the traditional DEA model. The evaluation index of the NPV and the internal rate of return may be negative in the charging price decision-making. Therefore, it is necessary to divide the input indices and output indices into groups and to process multiindex comprehensively before evaluation using DEA [39].

\section{Simulation Result and Discussion}

In this section, the simulation results and the performance of the proposed evaluation method can be solved using the MATLAB software. In order to test the effectiveness of the proposed method, this paper selects a charging station of Shandong province, China [40], and the strike price of the charging station is 0.82 yuan $/ \mathrm{kWh}$.

Three kinds of scenarios for pricing of EV charging stations are analyzed as follows:

Scenario 1: base scenario without considering the consumer classification.

Scenario 2: considering the consumer classification.

Scenario 3: considering the changes of subjective weight on criteria.

The $500 \mathrm{kV}$ power transmission system is constructed in PSCAD/EMTDC as shown in Figure 3. The system includes three transmission lines whose lengths are $100 \mathrm{~km}, 200 \mathrm{~km}$, and $100 \mathrm{~km}$, respectively. R1 and R2 are the two relays on the middle line. Now, the new traveling wave polarity comparison protection can be studied by different fault locations and different fault types.

5.1. Scenario 1: The Pricing of EV Charging Stations without considering the Consumer Classification. Under the scenario without considering the consumer differences, this paper selects the typical consumers as an example, and the daily distance driven range of typical consumers is $75 \mathrm{~km}$ [24]. The profitable charging price for the operators can be got with the basic method on charging pricing, which is presented in Section 2.

The profitable charging price for operators is

$$
\left\{\pi_{c 1} \mid \pi_{c 1} \geq 2.28 \text { yuan } / \mathrm{kWh}\right\} \text {. }
$$

The acceptable charging price for consumers is

$$
\left\{\pi_{c 2} \mid \pi_{c 2} \leq 2.72 \text { yuan } / \mathrm{kWh}\right\} \text {. }
$$

Then, the acceptable reasonable charging price range $\pi_{c}$ for both operators and consumers is

$$
\left\{\pi_{c} \mid 2.28 \text { yuan } / \mathrm{kWh} \leq \pi_{c} \leq 2.72 \text { yuan } / \mathrm{kWh}\right\} .
$$

5.2. Scenario 2: The Pricing of EV Charging Stations considering the Consumer Classification. According to the above four types of consumer classification, four types of initial charging price schemes can be determined with the mentioned method, and the results are shown in Table 8. The calculated values of the corresponding evaluation indices $I_{1} \sim I_{7}$ are shown in Table 9. In order to ensure the comparability of the indices, the parameters of consumers are the unified value in the calculation of index $I_{1}$ and index $I_{2}$, which corresponding to the daily distance driven is $75 \mathrm{~km}$.

In general, first, the most important for comprehensive optimal decision-making of charging pricing is to ensure the economy of both operators and consumers. Second, if the applicability is slightly more important through comparing applicability with satisfaction, then the judgment matrix of evaluation criteria can be constructed with AHP, and it is as follows:

$$
\begin{aligned}
& \text { Economy Applicability Satisfaction } \\
& P=\left[\begin{array}{ccc}
1 & 1 & 1 \\
1 / 2 & 1 / 2 & 1 / 2 \\
1 / 3 & 1 / 3 & 1 / 3
\end{array}\right] \begin{array}{c}
\text { Economy } \\
\text { Applicability } . \\
\text { Satisfaction }
\end{array}
\end{aligned}
$$

The weight vector of the three criteria can be obtained with the square root method.

$$
w=\left(w^{P_{1}}, w^{P_{2}}, w^{P_{3}}\right)=(0.5396,0.2970,0.1634) .
$$

The optimal efficiency indices $V^{P_{1}}, V^{P_{2}}$, and $V^{P_{3}}$ can be calculated with DEA, and the results are shown in Table 10.

For the above four schemes, the comprehensive ranking for the weights of evaluation schemes can be calculated according to (13) and is shown in Table 11.

As shown in Table 11, the comprehensive ranking of each scheme are as follows: $2,4,3$, and 1 . It means that scheme 2 is the comprehensive optimal scheme; meanwhile, the acceptable reasonable charging price range $\pi_{c}$ for both operators and consumers is

$$
\left\{\pi_{c} \mid 2.28 \text { yuan } / \mathrm{kWh} \leq \pi_{c} \leq 2.32 \text { yuan } / \mathrm{kWh}\right\} .
$$

Further analysis shows that the efficiency indices $V^{P_{3}}$ of scheme 2 is 1 and $V^{P_{1}}$ and $V^{P_{2}}$ are, respectively, 0.7053 and 0.5533 . So, the applicability of the reasonable charging price 
TABLe 8: Consumer classification and the initial charging price schemes.

\begin{tabular}{lccccc}
\hline Schemes & $\begin{array}{c}\text { Classification (daily distance } \\
\text { driven) }\end{array}$ & $\begin{array}{c}\text { Daily distance driven of } \\
\text { consumers }(\mathrm{km})\end{array}$ & $\begin{array}{c}\text { Proportion of } \\
\text { consumers }(\%)\end{array}$ & $\begin{array}{c}\text { Average daily distance } \\
\text { driven }(\mathrm{km})\end{array}$ & $\begin{array}{c}\pi_{c 2}(\text { yuan/ } \\
\mathrm{kWh})\end{array}$ \\
\hline 1 & Short & $10-30$ & 25 & 20 & 0.99 \\
2 & Middle & $30-60$ & 27 & 45 & 2.32 \\
3 & Long & $60-90$ & 13 & 2.77 \\
4 & Longer & $90-120$ & 8 & 105 & 2.96 \\
\hline
\end{tabular}

Table 9: Index values of each initial charging price schemes.

\begin{tabular}{lcccccccc}
\hline Schemes & $I_{1}(\%)$ & $I_{2}$ (year) & $I_{3}$ (million yuan) & $I_{4}$ (year) & $I_{5}(\%)$ & $I_{6}$ & $I_{7}($ yuan $/ \mathrm{kWh})$ & $I_{8}(\mathrm{yuan} / \mathrm{kWh})$ \\
\hline 1 & 92 & 2 & -30.412 & $10^{6}$ & 25 & 0.0082 & 1.29 & 0.17 \\
2 & 19 & 12 & 1.076 & 15 & 27 & 0.0122 & 0.04 & 1.50 \\
3 & 5 & 16 & 11.73 & 9 & 13 & 0.0042 & 0.49 & 0.68 \\
4 & 1 & 21 & 16.229 & 8 & 8 & 0.0020 & 2.14 \\
\hline
\end{tabular}

TABLE 10: The optimal efficiency indices of each scheme.

\begin{tabular}{lccc}
\hline Schemes & $V^{P_{1}}$ & $V^{P_{2}}$ & $V^{P_{3}}$ \\
\hline 1 & 0.6667 & 0.7622 & 0.0035 \\
2 & 0.7053 & 0.5533 & 1 \\
3 & 0.7375 & 0.7738 & 0.1061 \\
4 & 0.6822 & 1 & 0.0839 \\
\hline
\end{tabular}

TABLE 11: Comprehensive ranking for the weights of evaluation scheme.

\begin{tabular}{lcccc}
\hline Schemes & 1 & 2 & 3 & 4 \\
\hline$Q_{i}$ & 0.2155 & 0.3401 & 0.2457 & 0.2527 \\
\hline
\end{tabular}

of the second type of consumers is not good. However, under the premise of ensuring the interests of both the consumers and operators, the overall satisfaction is very high. Therefore, the comprehensive ranking for the weights of evaluation scheme is the maximum. The $V^{P_{2}}$ of scheme 4 is 1 , but the charging price at this period is high for most consumers, which will seriously affect its overall economy and satisfaction and reduce its comprehensive ranking for weights. The economy of scheme 3 is optimal, but its applicability and satisfaction is low, and due to the importance of the two criteria that cannot be ignored, the comprehensive ranking for weight is relatively low. The charging price of scheme 1 for operators is too low, which will seriously influence its economy and satisfaction, and the applicability is also poorer; so, the comprehensive ranking for weight is the minimum.

Comparing the above two scenarios, it can be found that there exists feasible price range in both cases; however, the former price range upper limit is higher than the latter one. The latter considers different influences of charging prices on the benefits of all types of consumers, and on the basis of reasonable classification, the charging price determined using the AHP/DEA method can take the interests of most consumers into account; therefore, it is more reasonable.

5.3. Scenario 3: The Impact of Criteria Weight Changes on the Pricing of EV Charging Stations. In the comprehensive decision-making of charging price, the different importance degrees among criteria reflect the tendency and actual demand of decision makers and show the weights of criteria with AHP. At different stages of EV development, the role of charging price is different and lays particular emphasis on the formulation of price. So, the evaluation criteria weights with AHP will change accordingly. In this paper, the weights under three extreme situations are discussed, and the results are shown in Table 12. The judgment matrix corresponding to situation 1 is

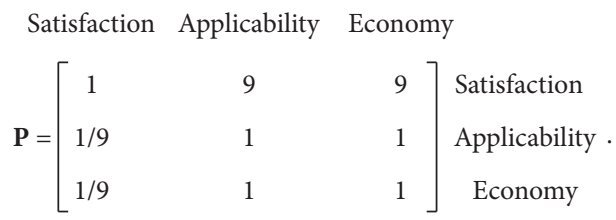

The same method may be easily adapted to obtain judgment matrix under other situations.

As shown in Table 12, when the criteria weights are assigned different values subjectively, the evaluation results will be different. Thus, different settings of evaluation criteria weights using AHP can realize the formulation of charging prices in terms of different requirements. On the other hand, although scheme 3 specially emphasizes on the applicability which will enable scheme 4 to become the comprehensive optimal scheme, the results of optimal and worst schemes are the same in other test cases. Therefore, it verifies that the proposed method for pricing of the EV charging station has 
TABle 12: Analysis of subjective weights under three extreme situations.

\begin{tabular}{lcccc}
\hline Situations & Characteristics & $w=\left(w^{p_{1}}, w^{p_{2}}, w^{p_{3}}\right)$ & $Q=\left(Q_{1}, Q_{2}, Q_{3}, Q_{4}\right)$ & Ranking schemes \\
\hline 1 & $\begin{array}{c}\text { Satisfaction is the most important, } \\
\text { ignore applicability and economy }\end{array}$ & $(0.0909,0.0909,0.8182)$ & $(0.0465,0.7248,0.1195,0.1092)$ & $2,3,4,1$ \\
& $\begin{array}{c}\text { Economy is the most important, } \\
\text { ignore applicability and satisfaction }\end{array}$ & $(0.8182,0.0909,0.0909)$ & $(0.2181,0.2992,0.2470,0.2358)$ & $2,3,4,1$ \\
3 & $\begin{array}{c}\text { Applicability is the most important, } \\
\text { ignore economy and satisfaction }\end{array}$ & $(0.0909,0.8182,0.0909)$ & $(0.2238,0.2457,0.2370,0.2935)$ & $4,2,3,1$ \\
\hline
\end{tabular}

better practicability. The DEA method can guarantee the role of objective factors in evaluation schemes; thus, even if the weights of criteria hierarchy have changed, the scientific and reasonable results most beneficial to majority consumers (scheme 2 has the highest proportion of consumers) can also be concluded.

\section{Conclusion}

The impacts of consumer differences on the formulation of charging prices cannot be ignored; therefore, this paper proposes a method on pricing of the EV charging station, which can take the interests of different consumers into account. This method realizes effective classification of consumers with the private EV by sensitivity analysis and piecewise linearization. Based on the formation of the initial pricing schemes for various types of consumers, the expert experience and the relative efficiency indices of each scheme can, respectively, deal with by using AHP and DEA methods properly. This method not only ensures the organic combination of subjective and objective factors in the scheme evaluation but also can reflect the emphasis of the evaluation scheme. Therefore, the comprehensive optimal charging price considering the economic interests of various types of consumers can be obtained.

Simulation results demonstrate that the formulation of charging price using the proposed method is more reasonable, when considering the fact that there exist differences among the EV consumers. Meanwhile, when the pricing requirements change, the proposed method can also be easily expressed by changing the relative weight of each criterion.

\section{Data Availability}

The data used to support this study are collected from the National Power Grid Corp. and China Electric Power Press. They are available in the public domain, so the authors have no restriction on that.

\section{Conflicts of Interest}

The authors declare that they have no conflicts of interest.

\section{Acknowledgments}

This work was supported in part by the National Science Foundation of China (Nos. 51477091 and 51407106) and in part by Youth Natural Science Foundation of China (No.
61803233) and the Fundamental Research Funds of Shandong University (2015WLJH43).

\section{References}

[1] Y. Zhang, P. You, and L. Cai, "Optimal charging scheduling by pricing for EV charging station with dual charging modes," IEEE Transactions on Intelligent Transportation Systems, vol. 20, no. 9, pp. 3386-3396, 2019.

[2] N. Kang, Y. Ren, F. M. Feinberg, and P. Y. Papalambros, "Public investment and electric vehicle design: a model-based market analysis framework with application to a USA-China comparison study," Design Ence, vol. 2, 2016.

[3] China National Government, Shandong Promote the Development of the Electric Vehicle Industry, China National Government, Jinan, China, 2016.

[4] China National Government, Tianjin Has Built 143 Seat Charging/Switching Stations Which Has Realized a Complete Coverage of Whole City, China National Government, Tianjin, China, 2016.

[5] G. Zarazua de Rubens, L. Noel, J. Kester, and B. K. Sovacool, "The market case for electric mobility: investigating electric vehicle business models for mass adoption," Energy, vol. 194, Article ID 116841, 2020.

[6] The National Development and Reform Commission (NDRC), Notice on Electricity Price Policy Issues Concerning Electric Vehicle, The National Development and Reform Commission (NDRC), Beijing, China, 2015.

[7] Shandong Province Government Order, Implementation Opinions on Speeding up the Installation of Fast Shandong Province Charging Infrastructure, Shandong Province Government Order, Jinan, China, 2016.

[8] J.-C. Tu and C. Yang, "Key factors influencing consumers' purchase of electric vehicles," Sustainability, vol. 11, no. 14, p. 3863, 2019.

[9] S.-C. Ma, Y. Fan, J.-F. Guo, J.-H. Xu, and J. Zhu, “Analysing online behaviour to determine Chinese consumers' preferences for electric vehicles," Journal of Cleaner Production, vol. 229, pp. 244-255, 2019.

[10] L. Zhang and Y. Liu, "Analysis of new energy vehicles industry policy in China's cities from the perspective of policy instruments," Energy Procedia, vol. 104, 2016.

[11] L. G. González, E. Siavichay, and J. L. Espinoza, "Impact of EV fast charging stations on the power distribution network of a Latin American intermediate city," Renewable and Sustainable Energy Reviews, vol. 107, 2019.

[12] Q. Zhang, Y. Hu, W. Tan, C. Li, and Z. Ding, "Dynamic timeof-use pricing strategy for electric vehicle charging considering user satisfaction degree," Applied Sciences, vol. 10, no. 9, p. 3247, 2020.

[13] N. Wang, Y. Liu, G. Fu, and Y. Li, "Cost-benefit assessment and implications for service pricing of electric taxies in 
China," Energy for Sustainable Development, vol. 27, pp. 137-146, 2015.

[14] C. D. Korkas, S. Baldi, P. Michailidis, and E. B. Kosmatopoulos, "A cognitive stochastic approximation approach to optimal charging schedule in electric vehicle stations," in Proceedings of the 2017 25th Mediterranean Conference on Control and Automation (MED), pp. 484-489, Valletta, Malta, July 2017.

[15] C. D. Korkas, S. Baldi, S. Yuan, and E. B. Kosmatopoulos, “An adaptive learning-based approach for nearly optimal dynamic charging of electric vehicle fleets," IEEE Transactions on Intelligent Transportation Systems, vol. 19, no. 7, pp. 2066-2075, 2018.

[16] T. P. Lyon, M. Michelin, A. Jongejan, and T. Leahy, "Is "smart charging" policy for electric vehicles worthwhile?" Energy Policy, vol. 41, pp. 259-268, 2012.

[17] K. Yuan, Y. Song, Y. Shao, C. Sun, and Z. Wu, "A charging strategy with the price stimulus considering the queue of charging station and EV fast charging demand," Energy Procedia, vol. 145, pp. 400-405, 2018.

[18] M. Pourabdollah, B. Egardt, N. Murgovski, and A. Grauers, "Effect of driving, charging, and pricing scenarios on optimal component sizing of a PHEV," Control Engineering Practice, vol. 61, pp. 217-228, 2017.

[19] T. Rui, C. Hu, G. Li, J. Tao, and W. Shen, "A distributed charging strategy based on day ahead price model for PVpowered electric vehicle charging station," Applied Soft Computing, vol. 76, pp. 638-648, 2019.

[20] E. Howland, "California PUC approves SDG\&E TOU pilot," Platts Megawatt Daily, p. 4-5, 2017.

[21] J. L. Paul, "Markets for power in the United States: an interim assessment," Energy Journal, vol. 1-36, 2006.

[22] C. Madina, I. Zamora, and E. Zabala, "Methodology for assessing electric vehicle charging infrastructure business models," Energy Policy, vol. 89, pp. 284-293, 2016.

[23] The National Development and Reform Commission, The Notice on Electricity Price Policy Issues Concerning the Electric Vehicle, The National Development and Reform Commission, Beijing, China, 2014.

[24] Beijing Development and Reform Committee, The Notice on Electric Vehicle Charging Fees Issues Concerning the Beijing City, Beijing Development and Reform Committee, Beijing, China, 2015.

[25] Xinjiang Province Government Order, Standard the EVs Charging Service Fee, Xinjiang Province Government Order, Urumqi, China, 2016.

[26] B. C. Farhar, D. Maksimovic, W. A. Tomac, and T. C. Coburn, "A field study of human factors and vehicle performance associated with PHEV adaptation," Energy Policy, vol. 93, pp. 265-277, 2016.

[27] L. Noel, G. Zarazua de Rubens, J. Kester, and B. K. Sovacool, "Understanding the socio-technical nexus of Nordic electric vehicle (EV) barriers: a qualitative discussion of range, price, charging and knowledge," Energy Policy, vol. 138, Article ID 111292, 2020.

[28] L. Wang, Z. L. Fu, W. Guo, R. Liang, and H. Y. Shao, "What influences sales market of new energy vehicles in China? Empirical study based on survey of consumers' purchase reasons," Energy Policy, vol. 142, 2020.

[29] K. Lu, S. Liu, X. S. Niu, W. L. Xue, Y. Zhu, and Z. J. Zhu, "Pricing method of electric vehicle charging by using costbenefit analysis," Journal of Power System and Automation, vol. 26, no. 3, pp. 76-80, 2014.
[30] Z. Wei, Y. Li, Y. Zhang, and L. Cai, "Intelligent parking garage EV charging scheduling considering battery charging characteristic," IEEE Transactions on Industrial Electronics, vol. 65, no. 3, pp. 2806-2816, 2018.

[31] X. Han, Z. Wei, Z. Hong, and S. Zhao, "Ordered charge control considering the uncertainty of charging load of electric vehicles based on Markov chain," Renewable Energy, vol. 161, pp. 419-434, 2020.

[32] K. Huang, Y. Wu, C. Wang, Y. Xie, and W. Gui, "A projective and discriminative dictionary learning for high-dimensional process monitoring with industrial applications," IEEE Transactions on Industrial Informatics, vol. 99, 2020.

[33] F. Sitorus, J. J. Cilliers, and P. R. Brito-Parada, “An integrated constrained fuzzy stochastic analytic hierarchy process method with application to the choice problem," Expert Systems with Applications, vol. 138, Article ID 112822, 2019.

[34] Y. Yu, X. Han, M. Yang, and J. Yang, "Probabilistic prediction of regional wind power based on spatiotemporal quantile regression," in Proceedings of the 2019 IEEE Industry Applications Society Annual Meeting, Baltimore, MD, USA, September 2019.

[35] Z. Ding, Y. Lu, K. Lai, M. Yang, and W. J. Lee, "Optimal coordinated operation scheduling for electric vehicle aggregator and charging stations in an integrated electricitytransportation system," International Journal of Electrical Power \& Energy Systems, vol. 121, Article ID 106040, 2020.

[36] L. Sun, J. Qiu, X. Han, X. Yin, and Z. Dong, "Per-use-share rental strategy of distributed BESS in joint energy and frequency control ancillary services markets," Applied Energy, vol. 277, Article ID 115589, 2020.

[37] S. Hardman, A. Jenn, G. Tal et al., "A review of consumer preferences of and interactions with electric vehicle charging infrastructure," Transportation Research Part D: Transport and Environment, vol. 62, pp. 508-523, 2018.

[38] X. Li, C. Liu, and J. Jia, "Ownership and usage analysis of alternative fuel vehicles in the United States with the 2017 national Household travel survey data," Sustainability, vol. 11, no. 8, p. 2262, 2019.

[39] C. Guo, Z. Peng, and J. Ding, "DEA index construction for comprehensive evaluation of sustainable development," China's Population, Resources and Environment, vol. 26, no. 3, pp. 9-17, 2016.

[40] J. Yang, H. Chen, M. Duan, and S. Qi, "Research on multistage planning of electric vehicle charging station," Shandong Electric Power Technology, vol. 42, no. 8, pp. 18-22, 2015. 